University of Nebraska - Lincoln

DigitalCommons@University of Nebraska - Lincoln

9-1-1997

\title{
High coercivity SmFeAIC thin films fabricated by multilayer sputtering
}

\author{
M.L. Yan \\ University of Nebraska - Lincoln \\ Z.S. Shan \\ University of Nebraska - Lincoln \\ Yi Liu \\ University of Nebraska-Lincoln, yliu@unl.edu \\ David J. Sellmyer \\ University of Nebraska-Lincoln, dsellmyer@unl.edu
}

Follow this and additional works at: https://digitalcommons.unl.edu/physicssellmyer

Part of the Physics Commons

Yan, M.L.; Shan, Z.S.; Liu, Yi; and Sellmyer, David J., "High coercivity SmFeAlC thin films fabricated by multilayer sputtering" (1997). David Sellmyer Publications. 73.

https://digitalcommons.unl.edu/physicssellmyer/73

This Article is brought to you for free and open access by the Research Papers in Physics and Astronomy at DigitalCommons@University of Nebraska - Lincoln. It has been accepted for inclusion in David Sellmyer Publications by an authorized administrator of DigitalCommons@University of Nebraska - Lincoln. 


\title{
High Coercivity SmFeAlC Thin Films Fabricated by Multilayer Sputtering*
}

\author{
M. L. Yan ${ }^{1,2}$, Z. S. Shan ${ }^{1}$, Y. Liu ${ }^{3}$, and D. J. Sellmyer ${ }^{1}$ \\ 'Behlen Laboratory of Physics and Center for Materials Research and Analysis \\ University of Nebraska, Lincoln, NE 68588-0113, USA \\ ${ }^{2}$ State Key Laboratory for Magnetism, Institute of Physics \\ Chinese Academy of Sciences, Beijing 100080, China \\ ${ }^{3}$ Department of Mechanical Engineering and Center for Materials Research and Analysis \\ University of Nebraska, Lincoln, NE 68588-0113, USA
}

\begin{abstract}
Multilayer sputtering of $\mathrm{SmFe} / \mathrm{C}(\mathrm{Al})$ plus appropriate thermal processing has been used to fabricate $\mathrm{SmFeC}$ thin films with Al substitution for Fe. It was found that the $\mathrm{SmFeAlC}$ thin films exhibited exceptionally high coercivities. A coercivity of $28 \mathrm{kOe}$ was realized for the thin film with structure of $\mathrm{Ta}(1000 \AA) /[\mathrm{SmFe}(40 \AA) /$ $\mathrm{C}(\mathrm{Al})(5 \AA)] \times 50 / \mathrm{Ta}(200 \AA)$ with subsequent annealing at $650^{\circ} \mathrm{C}$.
\end{abstract}

\section{INTRODUCTION}

$\mathrm{SmFeN}$ and $\mathrm{SmFeC}$ intermetallic compounds based on the rhombohedral $\mathrm{Th}_{2} \mathrm{Zn}_{17}$-type structure have been attracting much attention as potential candidates for permanent-magnet materials owing to their excellent magnetic properties[1,2]. For example, a room temperature coercivity of $15 \mathrm{kOe}$, saturation magnetization of $92.4 \mathrm{emu} / \mathrm{g}$, and Curie temperature of $624 \mathrm{~K}$ were reported for $\mathrm{Sm}_{2} \mathrm{Fe}_{14} \mathrm{Ga}_{3} \mathrm{C}_{1.5}$ [3]. Much effort has been devoted to the improvement of the intrinsic magnetic properties, such as the various elemental substitutions for $\mathrm{Fe}$ in the $\mathrm{SmFeC}$ materials. Recently, it has been shown that the substitution of $\mathrm{Ga}, \mathrm{Al}$ or $\mathrm{Si}$ for $\mathrm{Fe}$ can help only the formation of rhombohedral $\mathrm{Th}_{2} \mathrm{Zn}_{17}$-type rare-earth iron compounds, but also is very effective in raising the value of the anisotropy field $\mathrm{H}_{\mathrm{A}}$ [3-5]. For instance, the $\mathrm{SmFeC}$ compound with $\mathrm{A} 1$ substation for $\mathrm{Fe}$ has $\mathrm{H}_{\mathrm{A}}=110 \mathrm{kOe}$, which compares with $53 \mathrm{kOe}$ for the $\mathrm{SmFeC}$ compound[5]. Also, in the optimum case, a coercivity of $9.4 \mathrm{kOe}$ was obtained in a bulk specimen of $\mathrm{Sm}_{2} \mathrm{Fe}_{15} \mathrm{Al}_{2} \mathrm{C}_{1.5}$ compound[6]. It is of interest, therefore, to see whether similar coercivities can be realized in SmFeAlC thin films, which is required for modern magnetoelectronic device applications.

\section{EXPERIMENTS}

SmFeAlC thin films were prepared in a DC magnetron sputtering system using a composite $\mathrm{Sm}_{2} \mathrm{Fe}_{17}$ alloy target and a composite graphite(Al) target. The overall composition of the target is estimated to be $\mathrm{Sm}_{2} \mathrm{Fe}_{5} \mathrm{Al}_{1} \mathrm{C}_{1.5}$. In order to compensate for the loss of Sm during sputtering, several extra pieces of Sm were mounted on the SmFe target. Thin films were prepared in an argon pressure of 5 mTorr with base pressure better than $3 \times 10^{-7}$ Torr. The deposition rates were about $5 \AA / \mathrm{sec}$ for $\mathrm{SmFe}$ and $2 \AA / \mathrm{sec}$ for $\mathrm{C}(\mathrm{Al})$, respectively. First, multilayered $\mathrm{SmFe} / \mathrm{C}(\mathrm{Al})$ thin films with the structure of $\mathrm{Si} / \mathrm{Ta}(\mathrm{X}) /[\mathrm{Sm}(40 \AA) /(\mathrm{C}(\mathrm{Al})(\mathrm{Y} \AA)] \times \mathrm{N} / \mathrm{Ta}(200 \AA)$ were prepared

*Research supported by DOE Grants DEFG02-86ER45262 and Uni. of Chicago 95-47DH-00, and CMRA. at ambient temperature, where $\mathrm{X}$ is the thickness of $\mathrm{Ta}$ underlayer, $\mathrm{Y}$ is the thickness of $\mathrm{C}(\mathrm{Al})$ layer, and $\mathrm{N}$ is the number of $\mathrm{SmFe} / \mathrm{C}(\mathrm{Al})$ bilayers, respectively. The films were then thermal annealed at various temperatures in a vacuum of $5 \times 10^{-7}$ Torr for $5 \mathrm{~min}$.

The composition of the thin films was checked by energy dispersive $\mathrm{X}$-ray analysis (EDX) attached to a scanning electron microscope (SEM) and $\mathrm{x}$-ray fluorescence (XRF). The result for a film with high coercivity ( $28 \mathrm{kOe}$ ) indicated a stoichiometry of $\mathrm{Sm}_{2} \mathrm{Fe}_{52} \mathrm{Al}_{08} \mathrm{C}_{\mathrm{X}}$. The structure was analyzed by $\mathrm{x}$-ray diffraction and HRTEM. The magnetic properties were measured with an alternating gradient force magnetometer (AGFM) and SQUID magnetometer.

\section{RESULTS}

Figure 1 shows the coercivity $\mathrm{H}_{\mathrm{c}}$ of $\mathrm{SmFeAlC}$ thin films as a function of the thickness of the $\mathrm{C}(\mathrm{Al})$ layer. It is seen that the

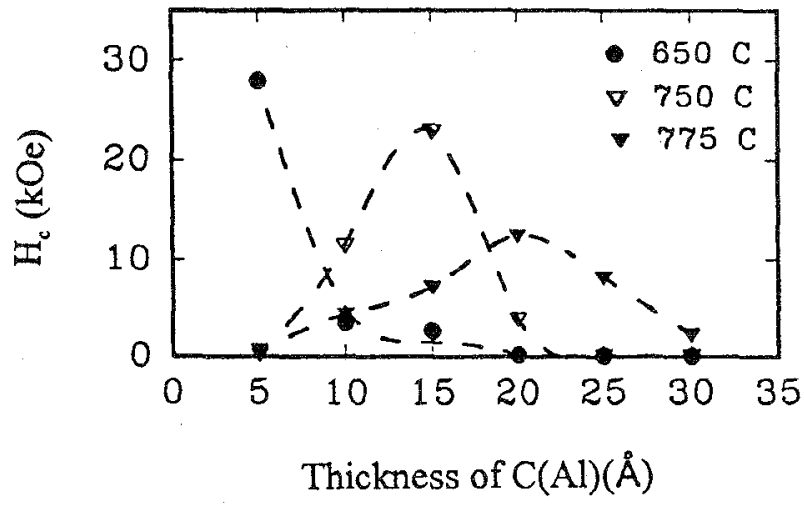

Fig.1. Coercivity vs. thicknesses of C(Al) layer for $\mathrm{Si} / \mathrm{Ta}(1000 \AA) /$ $[\mathrm{SmFe}(40 \AA) /(\mathrm{Al})(\mathrm{Y} \AA)] \times 50 / \mathrm{Ta}(200 \AA) . \mathrm{Y}$ is the thickness of the $\mathrm{C}(\mathrm{Al})$ layer. Thin films annealed at $650^{\circ} \mathrm{C}, 750^{\circ} \mathrm{C}$, and $775^{\circ} \mathrm{C}$ for $5 \mathrm{~min}$.

coercivity $\mathrm{H}_{\mathrm{c}}$ of the $\mathrm{SmFeAlC}$ thin films strongly depends on the thickness of the C(Al) layer and annealing condition. Depending on the thicknesses of the $\mathrm{C}(\mathrm{Al})$ layer and annealing temperature, three types of behaviors are seen in Fig.1: (1) $\mathrm{H}_{c}$ shows a peak with the variation of the C(A1) layers. This behavior was also observed earlier in our reported SmFeSiC thin films[7]. (2)The peaks of $\mathrm{H}_{c}$ move toward larger thicknesses of the $C(\mathrm{Al})$ layer with an increase of the annealing temperature. As seen in Fig.1, the maximum coercivity of the thin films appears at $15 \AA \mathrm{C}(\mathrm{Al})$ layer when thin films were annealed at $750^{\circ} \mathrm{C}$, whereas this maximum moves to $20 \AA \mathrm{C}(\mathrm{Al})$ layer when the annealing temperature was increased to $775^{\circ} \mathrm{C}$. (3)The maximum coercivities decrease with an increase of the 
annealing temperature. When the thin film was annealed at $650^{\circ} \mathrm{C}$, a coercivity of $28 \mathrm{kOe}$ was obtained for the thin film with structure of $\mathrm{Ta}(1000 \AA) /[\mathrm{SmFe}(40 \AA) / \mathrm{C}(\mathrm{Al})(5 \AA)] \times 50 / \mathrm{Ta}$ $(200 \AA)$. However, when the thin film was annealed at $775^{\circ} \mathrm{C}$, a coercivity of the thin film with the structure of $\mathrm{Ta}(1000 \AA) /[\mathrm{SmFe}(40 \AA) / \mathrm{C}(\mathrm{Al})(20 \AA)] \times 50 / \mathrm{Ta}(200 \AA)$

$13.5 \mathrm{kOe}$. These results indicate that magnetic properties of SmFeAlC thin films are highly sensitive to the ratio of SmFe to $\mathrm{C}(\mathrm{Al})$ and annealing temperature.

It is well known that a favorable microstructure is essential to obtain high coercivity in magnetic materials, because the grain size and shape, the defect type and distribution, and the grain boundary structure affect the domain structure and its wall movement, and thus control the coercivity of a magnetic material. In addition, it was reported that in magnetic thin films grain size and texture of magnetic layer were closely related to its underlayer[8]. For example, magnetic properties of $\mathrm{CoCrPt}[9]$ and $\mathrm{SmCo}[10,11]$ thin films were improved by the presence of a $\mathrm{Cr}$ underlayer[9]. By using Ta underlayer, similar behaviors have been observed in $\mathrm{SmFeSiC}$ thin films[7]. Based on the same idea, we deposited the SmFeAlC thin films on $\mathrm{Si}$ substrates with $\mathrm{Ta}$ underlayer. Our results show that magnetic properties are improved by the presence of the $\mathrm{Ta}$ underlayer. Figure 2 shows a dependence of $H_{c}$ and $M_{s}$ of
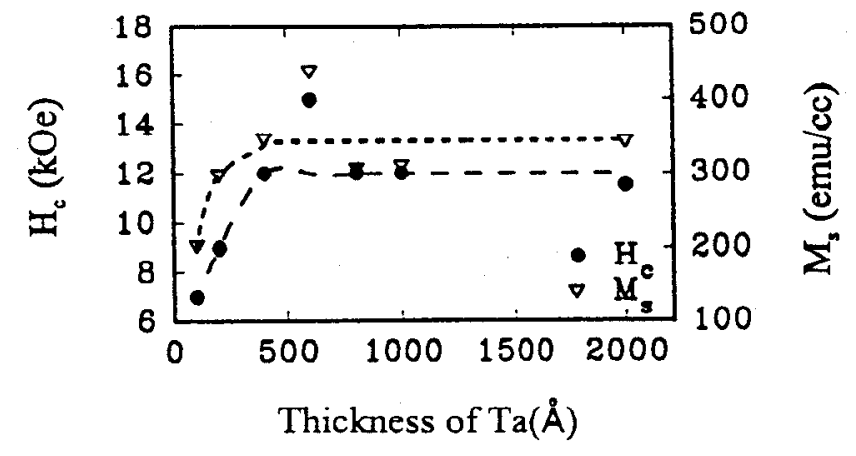

Fig.2. Dependence of $\mathrm{H}_{c}$ and $\mathrm{M}_{\mathrm{c}}$ of SmFeAlC thin films on the thickness of Ta underlayer.

SmFeAlC thin films on the Ta underlayer thickness. It is seen that both $\mathrm{H}_{\mathrm{c}}$ and $\mathrm{M}_{\mathrm{s}}$ increase with increasing the thickness of the Ta underlayer up to about $400 \AA$, and then remain nearly constant with the Ta underlayer thickness increasing further. TEM images show grain sizes in the range of 15 nanometers. Figure 3 shows a bright field TEM micrograph of a SmFeAlC thin film. Attempts at structural analysis of SmFeAlC thin films by $\mathrm{x}$-ray diffraction have not been successful because no characteristic crystalline peaks were observed on the diffraction pattern except peaks of $<002\rangle$ texture of $T a$ and $\langle 111\rangle$ texture of $\mathrm{Si}$. This result is consistent with other observations of SmCo and $\mathrm{SmFeSiC}$ thin films by Shan et al. [8] and Zhang et al. [7]. Probably this is attributed to small SmFe crystallites normally obtained with these sputter-deposited rare-earth thin films, which are in the so-called $x$-ray amorphous states. Further efforts for analyzing crystal structure of the magnetic phase are in progress by convergent beam electron diffraction and HRTEM.

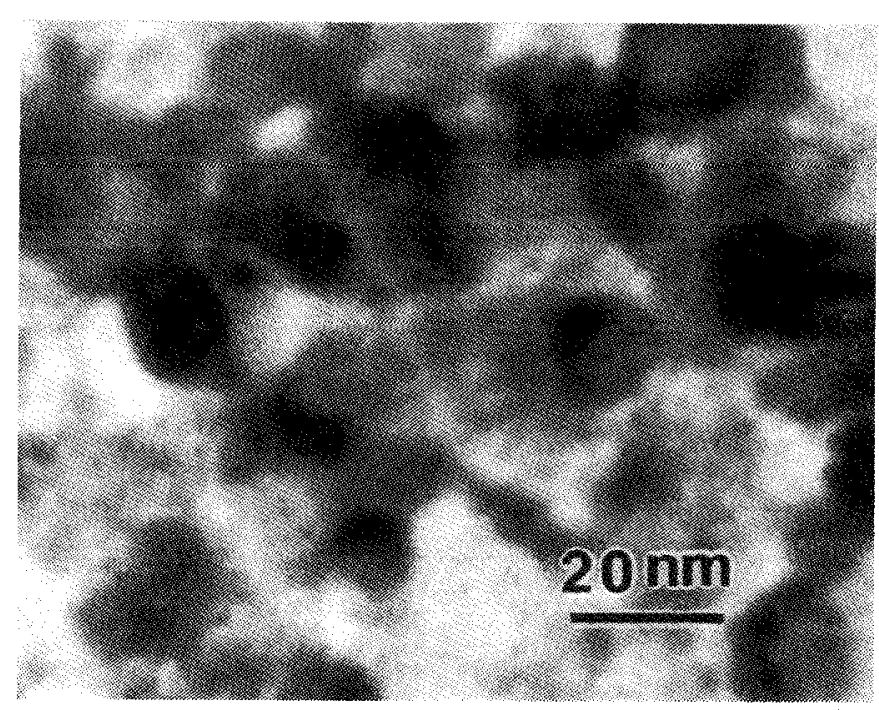

Fig.3.Bright field TEM micrograph of $\mathrm{Si} / \mathrm{Ta}(1000 \AA) /[\mathrm{SmFe}(40 \AA) /$ $\mathrm{C}(\mathrm{Al})(5 \AA)] \times 50 / \mathrm{Ta}(200 \AA)$ thin film after annealing at $650^{\circ} \mathrm{C}$ for $5 \mathrm{~min}$. The grain size is about $150 \AA$.

Figure 4 shows a coercivity of $\mathrm{SmFeAlC}$ thin film as a function of the number of $\mathrm{SmFe} / \mathrm{C}(\mathrm{Al})$ bilayers, that is, the relationship between coercivities and the total thickness of films. It can be seen that the coercivities of the thin film increase when the total thicknesses of the thin films increase from $500 \AA$ to $1500 \AA$, and then remain nearly constant with further increase of the film thickness. This result suggests that the hard magnetic phase does not appear until the thickness of the SmFeAlC layer is larger than $1000-1500 \AA$.

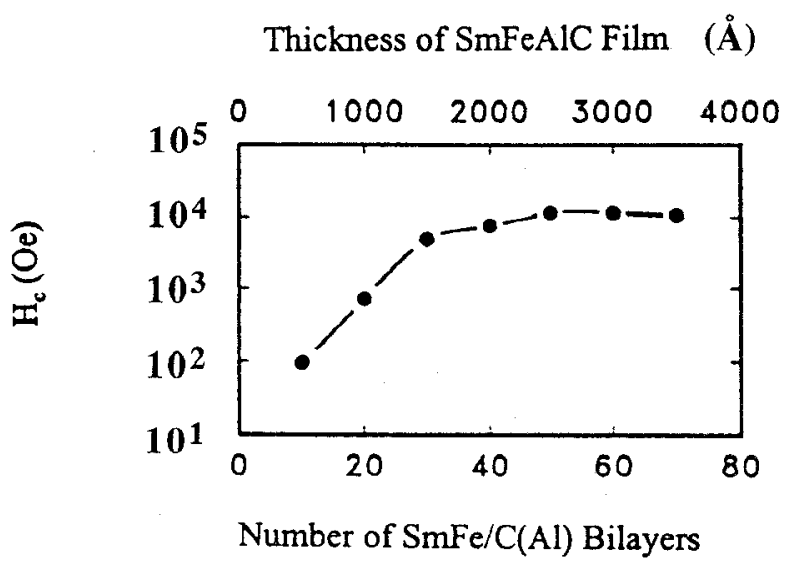

Fig.4 Coercivity of $\mathrm{Si} / \mathrm{Ta}(1000 \AA) /[\mathrm{SmFe}(40 \AA) / \mathrm{C}(\mathrm{Al})(10 \AA)] \times \mathrm{N} / \mathrm{Ta}(200 \AA)$ thin films on the number of $\mathrm{SmFe} / \mathrm{C}(\mathrm{Al})$ bilayer $\mathrm{N}$, that is, the relationship between coercivities and the total thickness of the SmFeAlC thin films. Thin films after annealing at $750^{\circ} \mathrm{C}$ for $5 \mathrm{~min}$.

A typical hysteresis loop of SmFeAlC thin film is shown in Fig. 5. Loops were measured at room temperature by the SQUID with a maximum applied field of $55 \mathrm{kOe}$. an in-plane coercivity as high as $28 \mathrm{kOe}$ was realized in the $\mathrm{SmFeAlC}$ thin films. The saturation magnetization is about $340 \mathrm{emu} / \mathrm{cc}$. Loops for both in-plane and perpendicular directions are nearly the same, which means that the SmFeAlC thin films prepared by this method are approximately isotropic. The kink near zero field suggests either the presence of a second soft phase or a 
low field nucleation phenomena that initiates magnetization reversal.

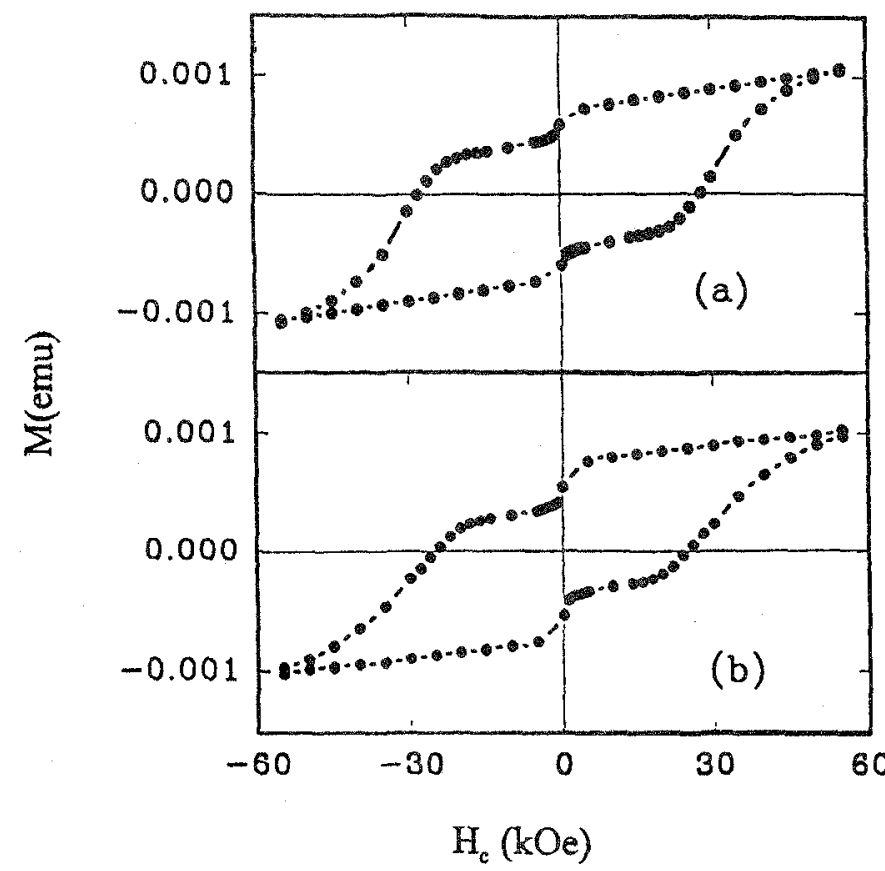

Fig.5 Hysteresis loop of the SmFeAlC thin film with the structure of $\mathrm{Si} / \mathrm{Ta}(1000 \AA) /[\mathrm{SmFe}(40 \AA) / \mathrm{C}(\mathrm{Al})(5 \AA)] \times 50 / \mathrm{Ta}(200 \AA)$. Thin film after annealing at $650^{\circ} \mathrm{C}$. (a) Applied field is in-plane; (b) Applied field is perpendicular to the thin film plane.

To the best of our knowledge, the exceptionally high coercivity of $28 \mathrm{kOe}$ found for the first time here in SmFeAlC thin films is comparable to that of SmCo thin films (about 31 $\mathrm{kOe}$ )[12], and is higher than that of $\mathrm{SmFeSiC}$ thin films (about $7.2 \mathrm{kOe})[7]$ and $\mathrm{SmFeAlC}$ compounds $(9.2 \mathrm{kOe})[6]$. The reason for the higher coercivity in SmFeAlC thin films is probably associated with the specific nanostructure and/or defects obtained with these sputter-deposited thin films. The saturation magnetization of SmFeAlC thin films, however, is somewhat lower, although it is the same order of the magnitude to that of SmCo thin films. The reason for this is that the replacement of $\mathrm{Fe}$ by $\mathrm{Al}$, which is nonmagnetic, leads to a considerable reduction of saturation magnetization. The effort to adjust the composition of SmFeAlC thin films is in progress in order to improve the saturation magnetization. The dependence of high $\mathrm{H}_{\mathrm{c}}$ on SmFeAl composition is unclear now but it has been shown that the $\mathrm{H}_{\mathrm{c}}$ strongly depends on the $\mathrm{Al}$ content. Further studies of the effect of Al addition on the magnetic properties are under way.

\section{CONCLUSION}

Thin films of SmFeAlC having interesting magnetic properties can be successfully fabricated using $\mathrm{SmFe} / \mathrm{C}(\mathrm{Al})$ multilayer sputtering plus thermal processing. Thin film with structure of $\mathrm{Si} / \mathrm{Ta}(1000 \AA) /[\mathrm{SmFe}(40 \AA) /$ $\mathrm{C}(\mathrm{Al})(5 \AA)] \times 50 / \mathrm{Ta}(200 \AA)$, which was subsequently annealed at $650^{\circ} \mathrm{C}$, has a coercivity of $28 \mathrm{kOe}$. This exceptionally high value is considerably higher than the value obtained with bulk specimens of SmFeAlC compound, but these could be an altogether different composition and structure. However, the relationships between higher coercivity and the composition of the optimal thin films, and the crystal structure of a magnetic phase need to be further investigated in detail.

\section{ACKNOWLEDGMENT}

We are grateful for financial support to the Department of Energy and the Center for Materials Research and Analysis at The University of Nebraska, and Dr. J. P. Liu, Dr. S. Y. Zhang, and Dr. T. Y. Zhao for helpful assistance and discussion.

\section{REFERENCES}

[1] J. M. D. Coey and H. Sun, J. Magn. Magn. Mater. Vol. 87, 1990, pp. L25I-L254.

[2] J. M. D. Coey, H. Sun, Y. Otani, and D. P. F. Hurley, J. Magn. Magn. Mater. Vol. 98, 1990, 76-79.

[3] B. G. Shen, L. S. Kong, F. W. Wang, and L. Cao, Appl. Phys. Lett. Vol. 63, 1993, 2288-2290.

[4] B. G. Shen, F. W. Wang, L. S. Kong, L. Cao, and H. Q. Guo, J. Magn. Magn. Mater. Vol. 127, 1990, L267-L272.

[5] Z. H. Cheng, B. G. Sheng, F. W. Wang, J. X. Zhang, H. Y. Gong. and J.G. Zhao, J. Phys.: Condens. Matter Vol. 6, No. 14, 1994, L185-L190.

[6] J. X. Zhang, Z. H. Cheng, and B.G. Shen, J. Appl. Phys. Vol. 79, 1996, $5528-5530$.

[7] S. Y. Zhang, Z. S. Shan, Y. Liu, D.J. Sellmyer, T. Y. Zhao, J. G. Zhao and B. G. Shen, IEEE Trans. Magn., Vol. 32, No.5, 1996, 4550-4552.

[8] Z. Shan, S.S. Malhotra, S.H. Liou, M. Yu, and D. J. Sellmyer, J. Magn. Magn. Mater. Vol. 161, 1996, 323-336.

[9] T. Yogi, C. Tsang, T. A. Nguyen, K. Ju, L. Gormen and G. Castillo, IEEE Trans. Mag Vol. 26, 1990, 2271-2273.

[10] E. M. T. Velu and D. N. Lambeth, IEEE Trans. Mag Vol. 28, 1992, 3249-3254.

[11] E. M. T. Velu, d. N. Lambeth, J.T. Thornton, and P. E. Russel, J. Appl. Phys. Vol. 75, 1994, 6132-6134.

[12] S. S. Malhotra, Y. Liu, Z. S. Shan, S.H. Liou, D. C. Stafford, and D.J. Sellmyer, J.Appl. Phys. Vol. 79, 1996, 5958-5960. 